\title{
Assessing multiple predator, diurnal and search area effects on predatory impacts by ephemeral wetland specialist copepods
}

\author{
Ross N. Cuthbert (i) Tatenda Dalu • Ryan J. Wasserman • Cristián J. Monaco • \\ Amanda Callaghan $\cdot$ Olaf L. F. Weyl · Jaimie T. A. Dick
}

Received: 16 August 2019/Accepted: 22 November 2019/Published online: 29 November 2019

(C) The Author(s) 2019

\begin{abstract}
Predator-prey interaction strengths can be highly context-dependent. In particular, multiple predator effects (MPEs), variations in predator sex and physical habitat characteristics may affect prey consumption rates and thus the persistence of lower trophic groups. Ephemeral wetlands are transient ecosystems in which predatory copepods can be numerically dominant. We examine the interaction strengths of a specialist copepod Paradiaptomus lamellatus towards mosquito prey in the presence of conspecifics using a functional response approach. Further, we examine sex variability in predation rates
\end{abstract}

Handling Editor: Télesphore Sime-Ngando.

R. N. Cuthbert $(\bowtie) \cdot$ J. T. A. Dick

Institute for Global Food Security, School of Biological

Sciences, Queen's University Belfast,

Belfast BT9 5DL, Northern Ireland, UK

e-mail: rossnoelcuthbert@gmail.com

R. N. Cuthbert · O. L. F. Weyl

DSI/NRF Research Chair in Inland Fisheries and

Freshwater Ecology, South African Institute for Aquatic

Biodiversity (SAIAB), Makhanda 6140, South Africa

R. N. Cuthbert · A. Callaghan

Ecology and Evolutionary Biology, School of Biological

Sciences, University of Reading, Harborne Building,

Reading RG6 6AS, England, UK

T. Dalu

Ecology and Resource Management, University of Venda, Thohoyandou, Limpopo, South Africa of $P$. lamellatus under circadian and surface area variations. Then, we assess the influence of a cooccurring heterospecific predatory copepod, Lovenula raynerae, on total predation rates. We demonstrate MPEs on consumption, with antagonism between conspecific $P$. lamellatus predatory units evident, irrespective of prey density. Furthermore, we show differences between sexes in interaction strengths, with female $P$. lamellatus significantly more voracious than males, irrespective of time of day and experimental arena surface area. Predation rates by $P$. lamellatus were significantly lower than the heterospecific calanoid copepod $L$. raynerae, whilst heterospecific copepod groups exhibited the greatest

T. Dalu · R. J. Wasserman

South African Institute for Aquatic Biodiversity (SAIAB),

Makhanda 6140, South Africa

\section{R. J. Wasserman}

Department of Biological Sciences and Biotechnology,

Botswana International University of Science and

Technology, Palapye, Botswana

C. J. Monaco

School of Biological Sciences, University of Adelaide, Adelaide 5005, Australia

C. J. Monaco

Department of Zoology and Entomology, Rhodes

University, Makhanda 6140, South Africa 
predatory impact. Our results provide insights into the predation dynamics by specialist copepods, wherein species density, diversity and sex affect interaction strengths. In turn, this may influence population-level persistence of lower trophic groups under shifting copepod predator composition.

\section{Keywords Paradiaptomus lamellatus $\cdot$ Lovenula} raynerae $\cdot$ Calanoid copepod $\cdot$ Multiple predator effects $\cdot$ Functional response

\section{Introduction}

Predation is a fundamental biotic process which profoundly affects ecosystem structure, stability and functioning (Brooks and Dodson 1965; Paine 1980; Wasserman and Froneman 2013). Models applied to consumer-resource systems classically assumed functional equivalence of predators within populations (Volterra 1928; Lotka 1956; Rosenzweig and MacArthur 1963), limiting comprehensive quantifications of interaction strengths under shifting biotic contexts (e.g. predator sex or ontogenic stage). Yet, more recent work has recognised the need to account for individual consumer variability within populations (e.g. Hassell 1978; Ebenman and Persson 1988; Murdoch et al. 2003; Thorp et al. 2018). Moreover, as the effects of environmental change on species interactions are challenging to predict with certainty (Daufresne et al. 2009; Gilbert et al. 2014), quantifying context dependencies for predation is imperative for inferences of trophic interactions in changing environments (see Wasserman et al. 2016b).

Given that most ecological communities include multiple predators which share common resources, predator-predator exchanges can profoundly alter interaction strengths (Soluk 1993; Sih et al. 1998; Bolker et al. 2003; Wasserman et al. 2016c). An increasing body of work has examined the implications of multiple predators for prey risk (Schmitz 2007; Vance-Chalcraft et al. 2007; Griffin et al. 2013), and understanding combined predator interactions provides important insights for the implications of predator species loss for ecosystem function (Duffy et al. 2007). One classical ecological approach to quantify consumer-resource (e.g. predator-prey) interactions under context dependencies is through derivation of functional responses (FRs) (Solomon 1949; Holling 1959). Functional responses quantify how resource intake changes with variations in resource densities, and FR form and magnitude may influence stability of lower trophic groups (Murdoch and Oaten 1975; Dick et al. 2014). Three common FR types have been categorised: the linear Type I, inversely density-dependent Type II and sigmoidal Type III (Hassell 1978). As Type II FRs are characterised by high proportional consumption rates at low densities, they may be particularly destabilising for resources, whilst Type III FRs are thought to be more stabilising through low-density refuge effects (Murdoch and Oaten 1975). In Type II FRs, the attack rate parameter controls the initial slope of the curve whilst the handling time parameter controls the height of the FR asymptote (i.e. maximum feeding rate). Empirical studies show that greater magnitude FRs (i.e. high attack rates, low handling times, high maximum feeding rates) produce higher ecological impact on prey populations (Bollache et al. 2008; Dick et al. 2013; Taylor and Dunn 2018). Importantly, FRs offer a framework (Dick et al. 2014, 2017; Cuthbert et al. 2018a, b) to compare interaction strengths between different consumers whilst deciphering context dependencies, such as multiple predator effects (MPEs; see Sentis and Boukal 2018) and environmental change (e.g. Wasserman et al. 2016b).

Ephemeral wetlands provide excellent model systems for testing ecological theory (De Meester et al. 2005), and in arid regions, these systems are particularly vulnerable to environmental change (see Dalu et al. 2017a). Their impermanency elicits fundamentally different food web structures to other aquatic systems due to temporal variability in internal and external recruitment trends. In the early-mid stages of hydroperiod, ephemeral ponds are dominated by internal recruits which hatch from dormant eggs in the sediment (Greig et al. 2013; O'Neill et al. 2015). Therefore, for much of the hydroperiod, droughtadapted zooplankton groups such as calanoid copepods are most prevalent within the species assemblage in many ephemeral wetlands (e.g. Wasserman et al. 2018). However, despite their high prevalence and wide distribution (Dussart and Defaye 2001), the trophic interaction strengths between copepods and their resources and their susceptibility to environmental change remain poorly understood in biodiverse ephemeral systems (though see Wasserman et al. 
2016a; Cuthbert et al. 2018c, d). Sex ratios are known to differ over the course of the hydroperiod in ephemeral wetland specialist copepods due to selective processes such as predation (Wasserman et al. 2018). In turn, this may intensify impacts by predatory zooplankton on lower trophic groups if sex ratios become biased, given that females can have higher predatory impacts (Cuthbert et al. 2019a). However, these effects may also be dependent on the overall abundances of zooplankters, as offtake rates (product of functional and numerical responses) under low copepod abundances could be reduced. In addition, physical habitat characteristics may alter interactions between predatory copepods and their prey. Owing to periodic wetting and drying cycles, the surface area of ephemeral wetlands is highly dynamic spatiotemporally, and reductions in surface area may increase predator encounter rates with prey. Indeed, in an experimental context, search area has been shown to substantially alter the nature of consumer-resource dynamics (Yaşar and Özger 2005; Uiterwaal and DeLong 2018; Dalal et al. 2019). Day/night cycles may also modify predatory impacts of species which rely on visual cues (e.g. Townsend and Risebrow 1982); however, temporary pond specialist copepods have been suggested to be more reliant on hydromechanical cues for prey detection (Cuthbert et al. 2018d). Nevertheless, little is known about how these environmental factors interact to influence ephemeral wetland food webs, where copepods can be top predators.

Paradiaptomus lamellatus Sars 1895 is a predatory calanoid copepod which hatches from dormant eggs in the sediment within arid ephemeral ecosystems (see Wasserman et al. 2016a; Dalu et al. 2017b). This species has the potential to influence trophic dynamics in ephemeral ponds and particularly in the early-mid stages of hydroperiod when such copepod groups dominate higher trophic levels (Brendonck and De Meester 2003; Dalu et al. 2017b). Given the high densities of predators that hatch from the sediment in these systems, predator-predator con/heterospecific interactions, alongside physical habitat characteristics, may have marked effects on interaction strengths towards focal prey species. Therefore, the present study examines environmental context dependencies of consumer impact. Firstly, we use comparative FRs to quantify conspecific MPEs of P. lamellatus towards surface-dwelling larval mosquito prey. The previous research has found additive interactions among other copepod species (Cuthbert et al. 2019b). We subsequently examine how predation rates vary between sexes of this species and test whether circadian or surface area variations further influence consumption. Copepod feeding rates have been shown previously to be highest in gravid females (Laybourn-Parry et al. 1988; Cuthbert et al. 2019a), and prey detection is known to be reliant on hydromechanical cues (Hwang and Strickler 2001). Container dimensions have also been shown to influence consumer-resource interaction strength quantifications (Uiterwaal and DeLong 2018). Lastly, we examine $P$. lamellatus feeding rates in the presence of the heterospecific calanoid copepod Lovenula raynerae Suárez-Morales, Wasserman, Dalu 2015 (Suárez-Morales et al. 2015), with which $P$. lamellatus commonly coexists. We thus seek to provide information into how predator-prey interaction strengths in ephemeral aquatic food webs are modulated by emergent biotic and abiotic contexts. We thus predict that: (1) conspecifics of P. lamellatus will interact independently and thus FRs will combine additively; (2) consumption rates will be higher in females than males, reduced under higher surface areas and unaffected by circadian variations and; (3) overall feeding rates will be heightened in the presence of an additional heterospecific predatory copepod, given their tendency to occupy different parts of the water column.

\section{Materials and methods}

\section{Experimental organisms}

Adult $P$. lamellatus (female: $4.23 \pm 0.07 \mathrm{~mm}$; male: $3.85 \pm 0.08 \mathrm{~mm}$ ) and $L$. raynerae (female: $4.77 \pm 0.14 \mathrm{~mm}$; male: $4.40 \pm 0.10 \mathrm{~mm}$ ) were sampled from an ephemeral pond in Makhanda (Grahamstown), Eastern Cape, South Africa (33 $16^{\prime} 47.8^{\prime \prime} \mathrm{S}$, $26^{\circ} 35^{\prime} 39.8^{\prime \prime}$ E) during the 2017-2018 austral summer by towing a $64-\mu \mathrm{m}$ zooplankton net through the upper portion of the water column. Copepods were transported in source water to a controlled environment (CE) room at Rhodes University, Makhanda, maintained at $25 \pm 2{ }^{\circ} \mathrm{C}$ and under a 14:10 light/dark photoperiod regime. Copepods were housed in $25 \mathrm{~L}$ aquaria and starved in strained $(20-\mu \mathrm{m}$ filter) source water. The prey, larvae of the Culex pipiens mosquito 
complex, were cultured in the $\mathrm{CE}$ room using egg rafts collected from artificial container-style habitats within the Rhodes University campus on a diet of crushed rabbit food pellets ad libitum (Agricol, Port Elizabeth).

Experiment 1: Functional responses (FRs) and conspecific multiple predator effects (MPEs)

A factorial design was implemented with respect to 'predator group' (2 levels) and 'prey supply' (5 levels) to decipher FRs and MPEs of single and multiple $P$. lamellatus. Adult male P. lamellatus were supplied with $C$. pipiens larvae $(2.51 \pm 0.11 \mathrm{~mm})$ at five densities $(2,4,8,16$ and 32$)$ in arenas of $5.6 \mathrm{~cm}$ diameter containing $80 \mathrm{~mL}$ strained source water following copepod starvation for $48 \mathrm{~h}$. This range of prey densities was informed from pilot studies, which indicated necessary numbers to decipher asymptotic FR magnitudes. Following a 2-h period to allow larval prey acclimation within the experimental arenas, $P$. lamellatus were introduced either singularly or as a conspecific unit comprised of two individuals. Copepods were then allowed to feed undisturbed for $10 \mathrm{~h}$ during light conditions, after which the remaining live prey were counted. Four replicates were conducted within each treatment group, and controls comprised three replicates at each density in the absence of predators. Overall consumption was analysed using generalised linear models (GLMs) assuming a Poisson error distribution and log link with respect to the 'predator group' and 'prey supply' treatments, and their interaction. We followed Crawley (2007) for all models and removed insignificant terms and interactions stepwise and performed post hoc tests using Tukey's comparisons (Lenth 2018).

Functional response analyses were undertaken using the frair packages in R v3.4.4 (Pritchard et al. 2017; R Core Development Team 2018). We used logistic regression to infer FR types, whereby a significantly negative first-order term indicates a Type II response. To account for prey depletion during the experiment, we fit Rogers' random predator equation (Rogers 1972; Juliano 2001):

$N_{\mathrm{e}}=N_{0}\left(1-\exp \left(a\left(N_{\mathrm{e}} h-T\right)\right)\right)$

where $N_{\mathrm{e}}$ is the number of prey eaten, $N_{0}$ is the initial density of prey, $a$ is the attack constant, $h$ is the handling time, and $T$ is the total experimental period.
The Lambert $W$ function was used to fit Eq. 1 (Bolker 2008). A nonparametric bootstrapping procedure $(n=2000)$ was followed to generate $95 \%$ confidence intervals (CIs) around FR curves based on the attack rate and handling time parameters. This process allows density-dependent visual differences in FRs to be ascribed on the basis of CI con/divergence (e.g. Wasserman et al. 2016b).

Using the attack rate and handling time parameter estimates from single predator treatments (Eq. 1), we fit a population-dynamic model to predict consumption by multiple predators, following McCoy et al. (2012) and Sentis and Boukal (2018):

$\frac{\mathrm{d} N}{\mathrm{~d} t}=-\sum_{i=1}^{n} f_{i}(N) P_{i}$

where $N$ is the prey density, $P_{i}(i=1,2, \ldots, n)$ are the population densities of predators $i$ and $f_{i}(N)$ is the FR of predator $i$. The population-dynamic model has been shown to be more robust than other approaches, such as the multiplicative risk model, for inferences of MPEs (Sentis and Boukal 2018). To generate prey survival predictions (and thus consumption rates), initial values of $N$ and $P_{i}(i=1,2, \ldots, n)$ were set at the experimental prey and predator densities, with prey survival projected over the total experimental duration. We used a global sensitivity analysis that incorporated confidence intervals from single predator FR parameters via a Latin hypercube sampling algorithm (Soetaert and Petzoldt 2010).

To deduce emergent MPEs, we used consumption predictions from the population-dynamic model (Eq. 2) under each prey density (Sentis et al. 2017). The predicted interaction strengths were derived as the simulated proportion of available prey consumed at each density. Likewise, we calculated experimentally observed interaction strengths for conspecific predator pairs. Given that the predicted interaction strengths from the population-dynamic model are in the absence of non-trophic interactions, whilst experimentally observed interaction strengths include these interactions, we calculated non-trophic interaction strengths by subtracting the predicted estimates from those experimentally observed. Thus, a negative non-trophic interaction strength indicates antagonistic MPEs, whilst positive values indicate synergism. Owing to assumptions of parametric testing being violated, a Kruskal-Wallis test was used to derive whether the 
strength of non-trophic interactions was affected by initial prey density.

Experiment 2: Diurnal predation variabilities between sexes

We conducted a factorial experiment to evaluate the effects of 'sex' (2 levels), 'time' (2 levels) and 'surface area' (2 levels) on the predation efficacy of $P$. lamellatus. Adult gravid female and male P. lamellatus were starved for $72 \mathrm{~h}$ before being added individually to arenas containing $30 \mathrm{C}$. pipiens larvae $(2.42 \pm 0.07 \mathrm{~mm})$. The numbers of prey were selected to approximate maximal densities from Experiment 1. After prey had acclimated for $2 \mathrm{~h}$ as before, male or female copepods were added individually to arenas containing $25 \mathrm{~mL}$ strained source water of either 3.5 or $5.6 \mathrm{~cm}$ diameter, with trials either conducted during day or night conditions. Predatory copepods were allowed to feed for $10 \mathrm{~h}$, after which they were removed and remaining live mosquito prey counted. This duration aligned with the current darkness regime of the $\mathrm{CE}$ room (see before). Five replicates were performed within each experimental group. Controls consisted of a replicate in each treatment group in the absence of predators. Generalised linear models (GLMs) assuming a quasi-Poisson error distribution with a log link were used to analyse consumption with respect to 'sex', 'time' and 'surface area' and their interactions, as residuals were found to be overdispersed.

Experiment 3: Heterospecific predatory impacts

We examined the predatory impacts of $P$. lamellatus in the presence of $L$. raynerae by quantifying predation in single (i.e. $1 \mathrm{P}$. lamellatus or $1 \mathrm{~L}$. raynerae separately) and mixed groups (i.e. 1 of each species in combination). Adult males of $L$. raynerae and $P$. lamellatus were starved for $24 \mathrm{~h}$ prior to experimentation before being presented to $50 \mathrm{C}$. pipiens larvae

Table 1 First-order terms derived from logistic regression of proportional prey consumption as a function of prey density, alongside functional response parameter estimates and $p$ values
$(3.33 \pm 0.13 \mathrm{~mm})$ in arenas of $5.6 \mathrm{~cm}$ diameter containing $25 \mathrm{~mL}$ strained source water. Again, prey were allowed to settle for $2 \mathrm{~h}$ prior to the addition of predators. Predators were allowed to feed for $18 \mathrm{~h}$, after which the remaining live prey were counted to quantify numbers killed. We conducted five replicates per experimental group, whilst controls consisted of three replicates in the absence of predatory copepods. Generalised linear models (GLMs) assuming a quasiPoisson error distribution and with a log link were used to compare consumption rates between predator treatments, with Tukey's comparisons used for multiple pairwise tests (Lenth 2018).

\section{Results}

Experiment 1: Functional responses (FRs) and conspecific multiple predator effects (MPEs)

All control prey survived, indicating that all experimental deaths were due to copepod predation, which was also witnessed directly. Overall consumption did not differ between single and multiple $P$. lamellatus predator treatments $\left(\chi^{2}=0.18, d f=1, p=0.67\right)$, yet increased significantly under greater prey densities $\left(\chi^{2}=25.21, d f=4, p<0.001\right)$. There was no significant 'predator group $\times$ prey supply' interaction $\left(\chi^{2}=0.80, d f=4, p=0.94\right)$.

Type II FRs were inferred under both single and multiple predator treatments, as evidenced by significantly negative first-order terms (Table 1). Confidence intervals overlapped for single and multiple predator treatments, indicating a lack of significant difference in FRs across prey densities (Fig. 1).

Non-trophic interaction strengths were always negative (Fig. 2) and were not significantly affected by prey densities $\left(\chi^{2}=5.57, d f=4, p=0.23\right)$. Accordingly, antagonistic multiple predator effects were evidenced by interacting conspecific P. lamellatus irrespective of prey density.

arising from Rogers' random predatory equation for single and multiple Paradiaptomus lamellatus feeding on Culex pipiens larvae

\begin{tabular}{llll}
\hline Treatment & First-order term, $p$ & Attack rate, $p$ & Handling time, $p$ \\
\hline$P$. lamellatus $\times 1$ & $-0.04,0.02$ & $0.47,0.01$ & $0.16,0.01$ \\
$P$. lamellatus $\times 2$ & $-0.05,0.001$ & $0.74,0.04$ & $0.26,<0.001$ \\
\hline
\end{tabular}




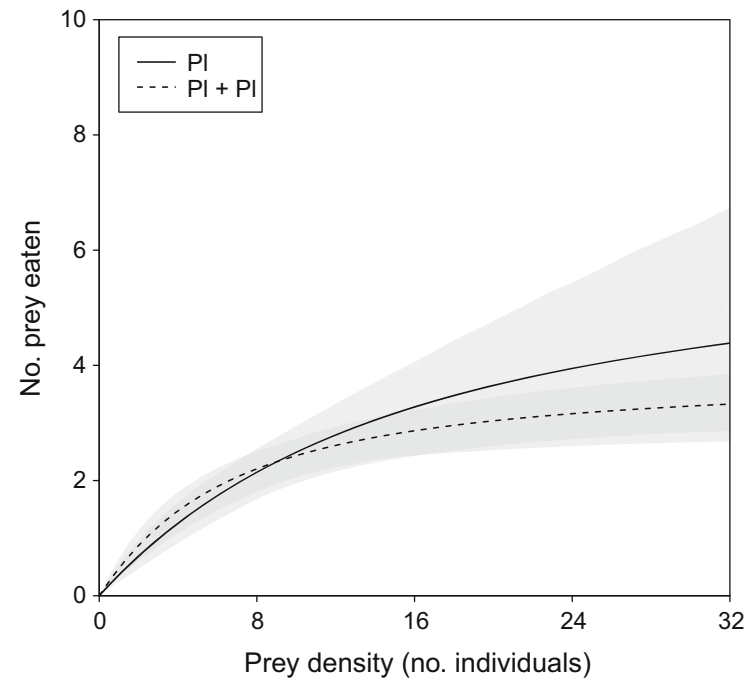

Fig. 1 Functional responses of Paradiaptomus lamellatus (Pl) feeding on Culex pipiens larvae individually and in predatory units of two individuals. Shaded areas are bootstrapped $95 \%$ confidence intervals

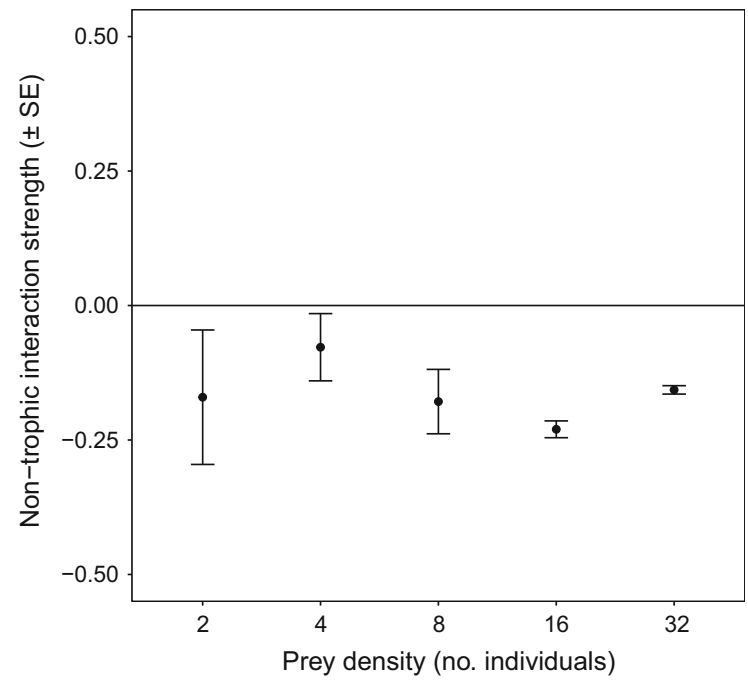

Fig. 2 Non-trophic interaction strengths of conspecific pairs of Paradiaptomus lamellatus feeding on Culex pipiens larvae across prey densities. The solid black line indicates neutral nontrophic interactions, whilst negative values indicate antagonistic interactions. Means are $\pm \operatorname{SE}(n=4$ per experimental group)

Experiment 2: Diurnal predation variabilities between sexes

Control survival in predator-free treatments was $100 \%$, and so experimental deaths were assumed to be due to predation by copepods. Significantly more prey were killed by female $P$. lamellatus than by males overall $\left(F_{1,38}=48.71, p<0.001\right.$; Fig. 3$)$. There was no significant difference in consumption rates during day or night $\left(F_{1,36}=0.49, p=0.49\right)$ or between different arena surface area treatments $\left(F_{1,37}=3.62\right.$, $p=0.07$ ). Further, the higher predation rates displayed by females were robust to both diurnal and arena surface area variations, with all interaction terms in the model found to be non-significant (all $p>0.05$ ) (Fig. 3).

Experiment 3: Heterospecific predatory impacts

All control prey survived in predator-free treatments, and thus, experimental deaths were attributed to predation by copepods. Predation was significantly affected by the predator treatment group overall $\left(F_{2,12}=27.01, p<0.001 ;\right.$ Fig. 4$)$. Lovenula raynerae consumed significantly more prey than $P$. lamellatus individually $(z=3.96, p<0.001)$. There was no significant difference between $L$. raynerae individual predation and mixed multiple predator predation $(z=2.21, p=0.07)$, whilst, conversely, predation by single $P$. lamellatus was significantly lower than that of mixed copepod species groups $(z=4.88$, $p<0.001)$. Nevertheless, predatory impact tended to be highest under heterospecific treatment groups (Fig. 4).

\section{Discussion}

The integration of biotic context is imperative for robust quantifications of predatory impact within ecosystems. In particular, prey species seldom experience single predators in nature, and so thus understanding predator-predator interactions is pertinent to decipher overall interaction strengths towards lower trophic groups (Sih et al. 1998; Schmitz 2007; VanceChalcraft et al. 2007; Griffin et al. 2013; Wasserman et al. 2016c). The present study demonstrates contextdependent interaction strengths by copepods in ephemeral wetlands. Specifically, using FRs, we demonstrate that MPEs arising from conspecific copepod predatory units of $P$. lamellatus are antagonistic, resulting in risk reductions for basal prey compared to predictions in the absence of non-trophic interactions. Further, our results display differences in predatory impact based on sex, with female $P$. 


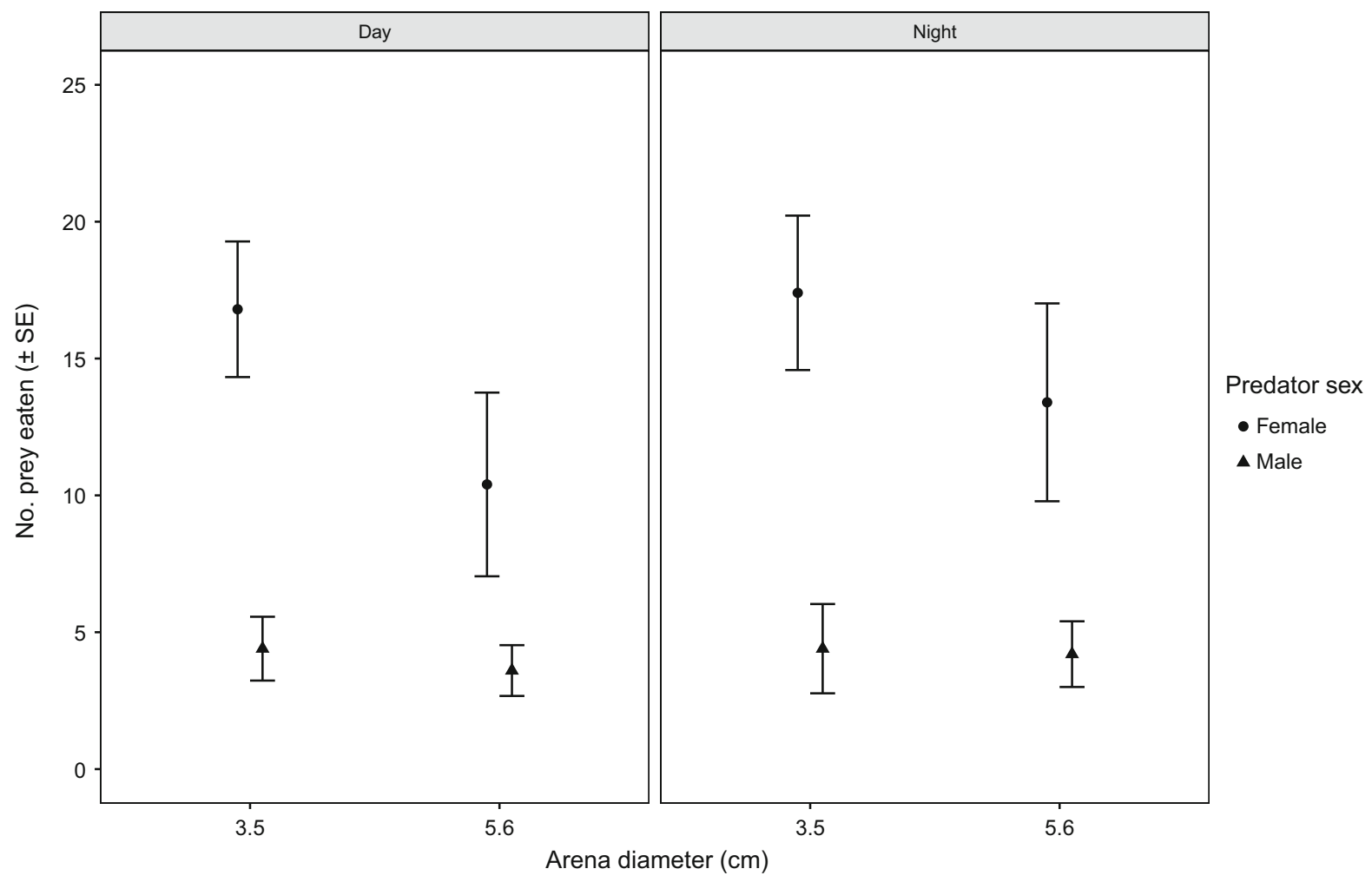

Fig. 3 Effect of Paradiaptomus lamellatus sex, diurnal regime and experimental arena surface area on consumption of Culex pipiens larvae. Means are $\pm \operatorname{SE}(n=5$ per experimental group)

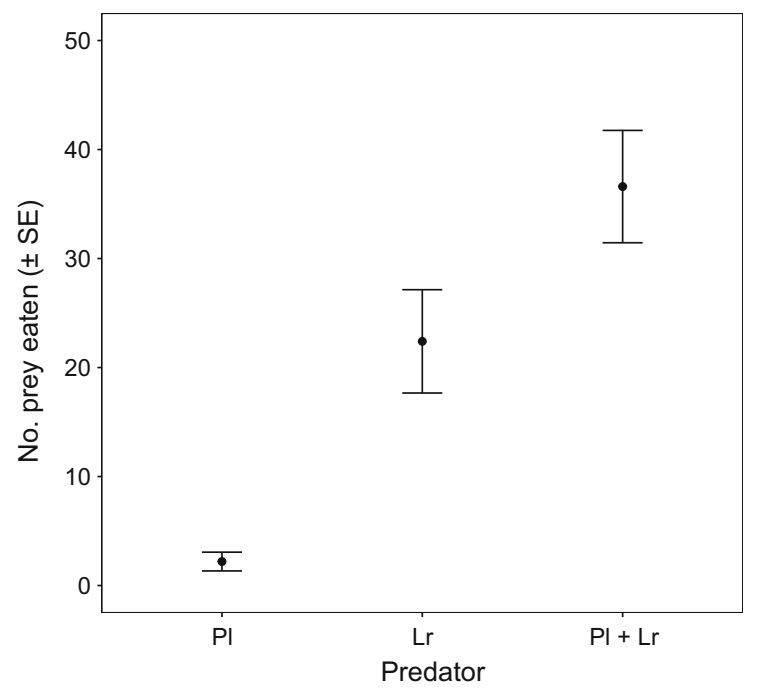

Fig. 4 Individual and multiple predator consumption by Paradiaptomus lamellatus (Pl) and Lovenula raynerae (Lr) towards larval Culex pipiens. Means are $\pm \mathrm{SE}(n=5$ per treatment group) lamellatus exerting significantly higher predation pressure on lower trophic groups than smaller-sized males. These effects were robust to abiotic effects surrounding diurnal cycling and aquatic surface area, which are both highly variable spatiotemporally in ephemeral aquatic habitats. Moreover, when P. lamellatus were within a heterospecific predatory unit alongside the controphic calanoid copepod L. raynerae, predation pressure tended to be heightened. This suggests that increasing predator diversity may increase ecological impacts on basal prey; however, whether other conspecific antagonisms balance this effect requires further investigation.

The outcomes of predator-predator interactions can manifest in a variety of ways for basal resources. Broadly, interactions can elicit either additive, antagonistic or synergistic outcomes (Soluk 1993; Losey and Denno 1998; Sih et al. 1998; Vance-Chalcraft and Soluk 2005; Barrios-O'Neill et al. 2014a; Wasserman et al. 2016c). Our results demonstrate that per capita prey risk reductions may result when multiple $P$. lamellatus are present. Such antagonism has 
additionally been displayed in other study systems in respect to both heterospecific (e.g. Soluk 1993; Barrios-O'Neill et al. 2014a) and conspecific (e.g. Wasserman et al. 2016c) predator groups. Yet, there has been a lack of work considering predatory zooplankters (Cuthbert et al. 2019b). Multiple $P$. lamellatus were shown to interact antagonistically in the present study, thus alleviating prey risk. Nontrophic interactions were always negative here, irrespective of prey density, in contrast to other studies where a unimodal relationship has been demonstrated (Sentis et al. 2017). Moreover, there were no significant differences in single and multiple predator consumption rates by $P$. lamellatus in the present study, and there were no differences in FR form exhibited between predator treatments towards culicid prey. Whilst attack rates tended to be higher in conspecific as compared to single copepod treatments, handling times were longer and thus maximum feeding rates were generally reduced. This corroborates our finding of negative non-trophic interactions, with multiple predators tending to reduce rather than increase feeding rates. Nevertheless, as Type II FRs are characterised by high per capita rates of resource acquisition at low prey densities, both single and multiple predator treatments could be destabilising to mosquito prey populations. Conversely, towards daphniid prey, Wasserman et al. (2016a) demonstrated that $P$. lamellatus displays a more sigmoidal FR, which may impart greater stability to this prey type. Therefore, the FR form of ephemeral wetland specialist copepod species appears to be variable depending on species-level compositional differences within lower trophic groups. In turn, these interspecific differences may contribute to prey species extirpations within temporary aquatic systems, with the FR type known to directly influence population stability (Dick et al. 2014). Here, this may indicate that larval mosquitoes are impacted to a greater degree than daphniids by $P$. lamellatus.

In the present study, interaction strengths of female $P$. lamellatus were shown to be significantly greater than male conspecifics. Many copepod species display marked sexual dimorphism (e.g. Oktsuka and Huys 2001) alongside behavioural variation (e.g. Wasserman et al. 2018), and this in turn can manifest in variable feeding rates (see Cuthbert et al. 2019a). Feeding rates of gravid female copepods are often elevated due to heightened energetic demands associated with their larger size coupled with requirements for progeny development (e.g. Laybourn-Parry et al. 1988; Cuthbert et al. 2019a). Paradiaptomus lamellatus was shown here to be able to handle larval culicid prey at consistent levels across diurnal and surface area variations, with the higher predation rates of females in comparison with males robust to these abiotic differences. These intraspecific differences in predation rate may be driven by body size or reproductive energy demands. However, the effects of surface area for other abiotic factors that may influence predation rates, such as temperature, require further elucidation given the observed effects of warming for interaction strengths in temporary ponds (Wasserman et al. 2016b; Cuthbert et al. 2019c). The lack of response to day/night differences suggests a reliance on hydromechanical cues to capture prey in $P$. lamellatus, as with other copepods (Hwang and Strickler 2001; Cuthbert et al. 2018d). Contrastingly, other studies have demonstrated species-specific responses to diurnal regime which affect feeding rates (e.g. Barrios-O'Neill et al. 2014b) and shown search area implications for FR parameterisation (e.g. Uiterwaal and DeLong 2018). Therefore, in ephemeral wetlands, predation pressures by calanoid copepods likely remain high across daily photoperiod undulations and throughout the various spatial stages of hydroperiod. Empirically, this may corroborate with the temporal constraints which characterise ephemeral systems and necessitate sustained resource intake rates in the 'race against time' to reproduce in zooplankters in these systems (De Meester et al. 2005).

In contrast to the antagonism displayed by conspecific units of $P$. lamellatus, the present study shows that predatory interactions can be enhanced when this species is in the presence of heterospecifics. Combined feeding rates were significantly elevated in the presence of the controphic calanoid copepod L. raynerae. This seeming lack of predator-predator interference may be driven by differences in spatial occupancy between the species, with $P$. lamellatus mainly benthic, whilst $L$. raynerae occupies the water column. Given that these calanoids often coexist in ephemeral wetlands, with both species recruited internally from dormant, drought-resistant eggs (Wasserman et al. 2016a), our results suggest that variations in predator diversity will have implications for basal prey, wherein higher densities of L. raynerae may intensify predation pressure. Indeed, L. raynerae has also been 
shown to demonstrate a destabilising Type II FR towards various basal prey types (Wasserman et al. 2016a; Cuthbert et al. 2018c).

Overall, we show that biotic context relating to predator-predator interactions and predator sexes can have marked, species-specific implications for interaction strengths in ephemeral wetlands, whilst abiotic effects were negligible. The ephemeral pond specialist copepod $P$. lamellatus interacted antagonistically with conspecifics, yet positive multiple predator interactions were indicated in the presence of the heterospecific specialist copepod $L$. raynerae. Copepod predation was robust to variations in experimental surface area, and predatory efficiencies were not altered by shifting day/night regimes. Accordingly, predatory impact by these copepods is likely unaffected by habitat heterogeneity over the hydroperiod in ephemeral wetlands, yet is affected by predator-predator exchanges and heightened in female copepods. Whilst little is known about trophic interactions driven by specialist copepods in ephemeral wetlands within arid regions, this study provides important insights into such interaction strengths under key environmental contexts.

Acknowledgements This study forms part of a Ph.D. studentship provided by the Department for the Economy, Northern Ireland. We thank Rhodes University for the provision of laboratory facilities. This study was partially funded by the National Research Foundation-South African Research Chairs Initiative of the Department of Science and Innovation (Inland Fisheries and Freshwater Ecology, Grant No. 110507).

\section{Compliance with ethical standards}

Conflict of interest The authors declare that they have no conflicts of interest.

Open Access This article is distributed under the terms of the Creative Commons Attribution 4.0 International License (http:// creativecommons.org/licenses/by/4.0/), which permits unrestricted use, distribution, and reproduction in any medium, provided you give appropriate credit to the original author(s) and the source, provide a link to the Creative Commons license, and indicate if changes were made.

\section{References}

Barrios-O'Neill D, Dick JTA, Emmerson MC, Ricciardi A, Mac-Isaac HJ, Alexander ME, Bovy HC (2014a) Fortune favours the bold: a higher predator reduces the impact of a native but not an invasive intermediate higher predator reduces the impact of a native but not an invasive intermediate predator. J Anim Ecol 83:693-701
Barrios-O'Neill D, Dick JTA, Ricciardi A, MacIsaac HJ, Emmerson MC (2014b) Deep impact: in situ functional responses reveal context-dependent interactions between vertically migrating invasive and native mesopredators and shared prey. Freshw Biol 59:2194-2203

Bolker BM (2008) emdbook: ecological models and data in R. Princeton University Press, Princeton

Bolker B, Holyoak M, Křivan V, Rowe L, Schmitz O (2003) Connecting theoretical and empirical studies of trait-mediated interactions. Ecology 84:1101-1114

Bollache L, Dick JTA, Farnsworth KD, Montgomery WI (2008) Comparison of the functional responses of invasive and native amphipods. Biol Lett 4:166-169

Brendonck L, De Meester L (2003) Egg banks in freshwater zooplankton: evolutionary and ecological archives in the sediment. Hydrobiologia 491:65-84

Brooks JL, Dodson SI (1965) Predation, body size, and composition of plankton. Science 150:28-35

Crawley MJ (2007) The R book. Wiley, Chichester

Cuthbert RN, Dick JTA, Callaghan A, Dickey JWE (2018a) Biological control agent selection under environmental change using functional responses, abundances and fecundities; the Relative Control Potential (RCP) metric. Biol Control 121:50-57

Cuthbert RN, Callaghan A, Dick JTA (2018b) Interspecific variation, habitat complexity and ovipositional responses modulate the efficacy of cyclopoid copepods in disease vector control. Biol Control 121:80-87

Cuthbert RN, Dalu T, Wasserman RJ, Callaghan A, Weyl OLF, Dick JTA (2018c) Calanoid copepods: an overlooked tool in the biocontrol of disease vector mosquitoes. J Med Entomol 55:1656-1658

Cuthbert RN, Dalu T, Wasserman RJ, Coughlan NE, Callaghan A, Weyl OLF, Dick JTA (2018d) Muddy waters: efficacious predation of container-breeding mosquitoes by a newly-described calanoid copepod across differential water clarities. Biol Control 127:25-30

Cuthbert RN, Dalu T, Wasserman RJ, Coughlan NE, Weyl OLF, Callaghan A, Froneman PW, Dick JTA (2019a) Sexskewed trophic impacts in ephemeral wetlands. Freshw Biol 64:359-366

Cuthbert RN, Callaghan A, Sentis A, Dalal A, Dick JTA (2019b) Additive multiple predator effects can reduce mosquito populations. Ecol Entomol https://doi.org/10.1111/een. 12791

Cuthbert RN, Weyl OLF, Wasserman RJ, Dick JTA, Froneman PW, Callaghan A, Dalu T (2019c) Combined impacts of warming and salinisation on trophic interactions and mortality of a specialist ephemeral wetland predator. Freshw Biol 64:1584-1592

Dalal A, Cuthbert RN, Dick JTA, Gupta S (2019) Water depthdependent notonectid predatory impacts across larval mosquito ontogeny. Pest Manag Sci 75:2610-2617

Dalu T, Wasserman RJ, Dalu MTB (2017a) Agricultural intensification and drought frequency increases may have landscape-level consequences for ephemeral ecosystems. Glob Change Biol 23:983-985

Dalu T, Wasserman RJ, Froneman PW, Weyl OLF (2017b) Trophic isotopic carbon variation increases with pond's hydroperiod: evidence from an Austral ephemeral ecosystem. Sci Rep 7:7572 
Daufresne M, Lengfellner K, Sommer U (2009) Global warming benefits the small in aquatic ecosystems. Proc Natl Acad Sci USA 106:12788-12793

De Meester L, Declerck S, Stoks R, Louette G, Van de Meutter F, De Bie T, Michels E, Brendonck L (2005) Ponds and pools as model systems in conservation biology, ecology and evolutionary biology. Aquat Conserv Mar Freshw Ecosyst 15:715-725

Dick JTA, Gallagher K, Avlijas S, Clarke HC, Lewis SE, Leung S, Minchin D, Caffrey J, Alexander ME, Maguire C, Harrod C, Reid N, Haddaway NR, Farnsworth KD, Penk M, Ricciardi A (2013) Ecological impacts of an invasive predator explained and predicted by comparative functional responses. Biol Invasions 15:837-846

Dick JTA, Alexander ME, Jeschke JM, Ricciardi A, MacIsaac HJ, Robinson TB, Kumschick S, Weyl OLF, Dunn AM, Hatcher MJ, Paterson RA, Farnsworth KD, Richardson DM (2014) Advancing impact prediction and hypothesis testing in invasion ecology using a comparative functional response approach. Biol Invasions 16:735-753

Dick JTA, Laverty C, Lennon JJ, Barrios-O’Neill D, Mensink PJ, Britton R, Médoc V, Boets P, Alexander ME, Taylor NG, Dunn AM, Hatcher MJ, Rosewarne PJ, Crookes S, MacIsaac HJ, Xu M, Ricciardi A, Wasserman RJ, Ellender BR, Weyl OLF, Lucy FE, Banks PB, Dodd JA, MacNeil C, Penk MR, Aldridge DC, Caffrey JM (2017) Invader relative impact potential: a new metric to understand and predict the ecological impacts of existing, emerging and future invasive alien species. J Appl Ecol 54:1259-1267

Duffy JE, Cardinale BJ, France KE, McIntyre PB, Thebault E, Loreau M (2007) The functional role of biodiversity in ecosystems: Incorporating trophic complexity. Ecol Lett 10:522-538

Dussart BH, Defaye D (2001) Introduction to the Copepoda. Guides to the Identification of the microinvertebrates of the continental waters of the world. Backhuys Publishers, Leiden

Ebenman B, Persson L (1988) Size structured populations: ecology and evolution. Springer, Berlin

Gilbert B, Tunney TD, McCann KS, DeLong JP, Vasseur DA, Savage V, Shurin JB, Dell AI, Barton BT, Harley CDG, Kharouba HM, Kratina P, Blanchard JL, Clements C, Winder M, Greig HS, O’Connor MI (2014) A bioenergetic framework for the temperature dependence of trophic interactions. Ecol Lett 17:902-914

Greig HS, Wissinger SA, McIntosh AR (2013) Top-down control of prey increases with drying disturbance in ponds: a consequence of non-consumptive interactions? J Anim Ecol 82:598-607

Griffin JN, Byrnes JE, Cardinale BJ (2013) Effects of predator richness on prey suppression: a meta-analysis. Ecology 94:2180-2187

Hassell MP (1978) The dynamics of arthropod predator-prey systems. Princeton University Press, Princeton

Holling CS (1959) Some characteristics of simple types of predation and parasitism. Can Entomol 91:385-398

Hwang JS, Strickler JR (2001) Can copepods differentiate prey from predator hydromechanically? Zool Stud 40:1-6
Juliano SA (2001) Nonlinear curve fitting: predation and functional response curves. In: Scheiner SM, Gurevitch J (eds) Design and analysis of ecological experiments. Oxford University Press, Oxford, pp 178-196

Laybourn-Parry J, Abdullahi BA, Tinson SV (1988) Temperature-dependent energy partitioning in the benthic copepods Acanthocyclops viridis and Macrocyclops albidus. Can J Zool 66:2709-2713

Lenth R (2018) emmeans: estimated marginal means, aka leastsquares means. $\mathrm{R}$ package version 1.2.4

Losey JE, Denno RF (1998) Positive predator-predator interactions: enhanced predation rates and synergistic suppression of aphid populations. Ecology 79:2143-2152

Lotka AJ (1956) Elements of mathematical biology, 2nd edn. Dover, New York

McCoy MW, Stier AC, Osenberg CW (2012) Emergent effects of multiple predators on prey survival: the importance of depletion and the functional response. Ecol Lett 15:1449-1456

Murdoch WW, Oaten A (1975) Predation and population stability. Adv Ecol Res 9:1-131

Murdoch WW, Briggs CJ, Nisbet RM (2003) Consumer-resource dynamics. Princeton University Press, Princeton

Oktsuka S, Huys R (2001) Sexual dimorphism in calanoid copepods: morphology and function. Hydrobiologia 453/454:441-466

O’Neill BJ, Rogers DC, Thorp JH (2015) Flexibility of ephemeral wetland crustaceans: environmental constraints and anthropogenic impacts. Wetl Ecol Manag 24:279-291

Paine RT (1980) Food webs: linkage, interaction strength and community infrastructure. J Anim Ecol 49:667-685

Pritchard DW, Paterson R, Bovy HC, Barrios-O'Neill D (2017) Frair: an $\mathrm{R}$ package for fitting and comparing consumer functional responses. Methods Ecol Evol 8:1528-1534

R Core Team (2018) R: a language and environment for statistical computing. R Foundation for Statistical Computing, Vienna

Rogers D (1972) Random search and insect population models. J Anim Ecol 41:369-383

Rosenzweig ML, MacArthur RH (1963) Graphical representation and stability conditions of predator-prey interactions. Am Nat 97:209-223

Schmitz OJ (2007) Predator diversity and trophic interactions. Ecology 88:2415-2426

Sentis A, Boukal DS (2018) On the use of functional responses to quantify emergent multiple predator effects. Sci Rep 8:11787

Sentis A, Gémard C, Jaugeon B, Boukal DS (2017) Predator diversity and environmental change modify the strengths of trophic and nontrophic interactions. Glob Change Biol 23:2629-2640

Sih A, Englund G, Wooster D (1998) Emergent impacts of multiple predators on prey. Trends Ecol Evol 13:350-355

Soetaert K, Petzoldt T (2010) Inverse modelling, sensitivity and Monte Carlo analysis in R using package FME. J Stat Softw 33:1-28

Solomon ME (1949) The natural control of animal populations. J Anim Ecol 18:1-35 
Soluk DA (1993) Multiple predator effects: predicting combined functional response of stream fish and invertebrate predators. Ecology 74:219-255

Suárez-Morales E, Wasserman RJ, Dalu T (2015) A new species of Lovenula Schmeil (Copepoda, Diaptomidae) from the Eastern Cape province of South Africa. Crustaceana 88:324-342

Taylor NG, Dunn AM (2018) Predatory impacts of alien decapod Crustacea are predicted by functional responses and explained by differences in metabolic rate. Biol Invasions 20:2821-2837

Thorp CJ, Alexander ME, Vonesh JR, Measey J (2018) Sizedependent functional response of Xenopus laevis on mosquito larvae. PeerJ 6:e5813

Townsend CR, Risebrow AJ (1982) The influence of light level on the functional response of a zooplanktonivorous fish. Oecologia 53:293-295

Uiterwaal SF, DeLong JP (2018) Multiple factors, including arena size, shape the functional responses of ladybird beetles. J Appl Ecol 55:2429-2438

Vance-Chalcraft HD, Soluk DA (2005) Multiple predator effects result in risk reduction for prey across multiple prey densities. Oecologia 144:472-480

Vance-Chalcraft HD, Rosenheim JA, Vonesh JR, Osenberg CW, Sih A (2007) The influence of intraguild predation on prey suppression and prey release: a meta-analysis. Ecology 88:2689-2696

Volterra V (1928) Variations and fluctuations of the number of individuals in animal species living together. J Cons Int Explor Mer 3:3-51
Wasserman RJ, Froneman PW (2013) Trophic level stabilityinducing effects of predaceous early juvenile fish in an estuarine mesocosm study. PLoS ONE 8:e61019

Wasserman RJ, Alexander ME, Barrios-O’Neill D, Weyl OLF, Dalu T (2016a) Using functional responses to assess predator hatching phenology implications for pioneering prey in arid temporary pools. J Plank Res 38:154-158

Wasserman RJ, Alexander ME, Weyl OLF, Barrios-O'Neill D, Froneman PW, Dalu T (2016b) Emergent effects of structural complexity and temperature on predator-prey interactions. Ecosphere 7:e01239

Wasserman RJ, Alexander ME, Dalu T, Ellender BR, Kaiser H, Weyl OLF (2016c) Using functional responses to quantify interaction effects among predators. Funct Ecol 30:1988-1998

Wasserman RJ, Weston M, Weyl OLF, Froneman PW, Welch RJ, Vink TJF, Dalu T (2018) Sacrificial males: the potential role of copulation and predation in contributing to copepod sex-skewed ratios. Oikos 127:970-980

Yaşar B, Özger Ş (2005) Functional response of Oenopia conglobata (L.) (Coleoptera: Coccinellidae) on Hyalopterus pruni (Geoffroy) (Homoptera: Aphididae) in three different size arenas. Turk J Entomol 29:91-99

Publisher's Note Springer Nature remains neutral with regard to jurisdictional claims in published maps and institutional affiliations. 